Im Journal Club referieren und kommentieren diese Experten für Sie Arbeiten aus der internationalen Fachliteratur.
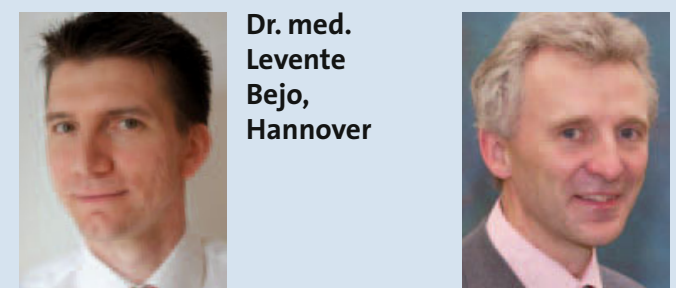

Dr. med. Martin Claßen, Bremen

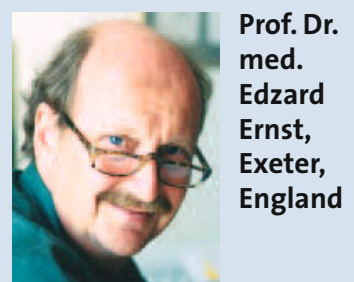

\title{
ADHS: Spielt die Geburtenfolge eine Rolle?
}

Die Reihenfolge, in der Geschwister auf die Welt kommen, wird als ein wichtiger Umweltfaktor angesehen. Israelische Wissenschaftler gingen nun der Frage nach, ob die Geburtenfolge auch bei ADHS eine Rolle spielt.

7 wei Neuropädiater aus Jerusalem $\angle$ untersuchten die Geburtsreihenfolge von 598 Kindern mit Aufmerksamkeitsdefizit-Hyperaktivitätsstörung (ADHS)

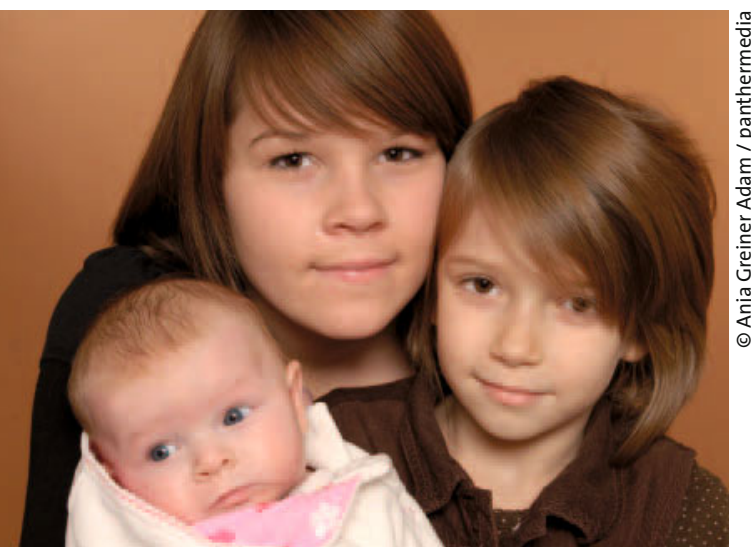

im Alter von 6-18 Jahren. 485 der Kinder hatten zwei und mehr Geschwister, $47,1 \%$ der Studienteilnehmer lebten sogar in Familien mit mehr als vier Kindern. $72 \%$ waren Jungen, 28\% Mädchen. Die Diagnose ADHS wurde von Neuropädiatern gemäß den DSM-IV-Kriterien gestellt.

Die Autoren fanden keinen signifikanten Einfluss der Geburtenfolge auf die Häufigkeit des Auftretens einer ADHS. Sie folgern daher, dass die Wahrscheinlichkeit, an ADHS zu erkranken, sowohl für ältere, mittlere oder jüngere

Ob Erstgeborene oder Nesthäkchen - auf das ADHS-Risiko hat dies keinen Einfluss.
Geschwister als auch für Einzelkinder fast gleich hoch ist.

Kommentar: Auch ein negatives Ergebnis kann informativ sein. Die Geburtenfolge wird als der Umweltfaktor mit dem stärksten Einfluss angesehen, der sowohl die kognitiven Fähigkeiten als auch die unterschiedlichen Verhaltensweisen betrifft: So sollen Einzelkinder ein erhöhtes Risiko für Verhaltensstörungen haben, während dieses beim ältesten von mehreren Geschwistern am niedrigsten ist. Diese wiederum zeigen eine erhöhte Vulnerabilität bezüglich externer familiärer Risikofaktoren. Jüngere Kinder hingegen haben weniger Lernschwierigkeiten. Die Beobachtung, dass die Geburtsreihenfolge bei AHDS keine Rolle spielt, bestätigt den starken genetischen Einfluss dieser Störung.

Dr. Kirsten Stollhoff

Berger I et al. Attention-deficit hyperactivity disorder (ADHD) and birth order. J Child Neurol 2009; 24: 692-6

glichen, die nicht reanimiert werden mussten.

Den Wissenschaftlern ging es vor allem um die Gruppe von Kindern mit einem verminderten IQ unter 80. Der verminderte IQ wurde sowohl bei postpartal wiederbelebten Kindern mit unmittelbar anschließender Enzephalopathie als auch ohne diese Komplikation gefunden. Verständlicherweise kam die IQ-Minderung in der ersten Gruppe deutlich häufiger vor (Odds Ratio 6,22 versus 1,65), jedoch war die Gruppe der wiederbelebten Neugeborenen ohne 